\title{
Principais Copolímeros Elastoméricos à Base de Butadieno Utilizados na Indústria Automobilística
}

\author{
Tereza C. J. Rocha, Bluma G. Soares \\ Instituto de Macromoléculas Professora Eloisa Mano, UFRJ \\ Fernanda M. B. Coutinho \\ Departamento de Processos Químicos, Instituto de Química, UERJ
}

\begin{abstract}
Resumo: Copolímeros elastoméricos à base de butadieno são amplamente utilizados na indústria automobilística. Dentre esses destacam-se os copolímeros de butadieno-estireno (SBR) e butadieno-acrilonitrila (NBR). O SBR apresenta maior importância comercial, devido a sua aplicação na produção de pneus. Quando SBR é utilizado juntamente com o homopolímero de butadieno BR-alto cis, excelentes propriedades são obtidas para sua aplicação na banda de rodagem de pneus. O copolímero elastomérico NBR é empregado em artefatos em que é necessária boa resistência a solventes orgânicos e a óleos. Nos últimos anos, as empresas automobilísticas e produtoras de pneumáticos vêm se preocupando com o meio-ambiente e, conseqüentemente, têm investido em novos processos de síntese, mais limpos, para a produção desses elastômeros. Assim, o objetivo deste artigo é apresentar uma revisão sobre dois importantes copolímeros elastoméricos à base de butadieno, SBR e NBR, abordando os processos de síntese, características principais, processamento e aplicações.
\end{abstract}

Palavras-chave: Copolímeros elastoméricos de butadieno-estireno, copolímeros elastoméricos de butadieno-acrilonitrila, processos de polimerização.

\section{The Most Important Butadiene Based Elastomers Employed in the Automotive Industry}

Abstract: Elastomer copolymers based on butadiene are widely applied in the automotive industry. Among those copolymers the most important ones are styrene-butadiene (SBR) and nitrile-butadiene (NBR). SBR presents higher commercial interest, due to its application in the tire production. When SBR is mixed with high cis-1,4 polybutadiene, excellent properties are attained for application on the pneumatics treads. NBR can be used in a wide variety of application areas requiring oil, fuel, and chemical resistance. In the last years, the automotive and pneumatic industries have been increasingly concerned with environmental issues, and have invested in synthesis processes for elastomers that are less aggressive to the environment. Thus, the purpose of this article is to present a review on two important butadiene elastomer copolymers, SBR and NBR, with emphasis on the polymerization processes. The main characteristics, processing and applications of these elastomers are also presented.

Keywords: Butadiene-styrene elastomer copolymers, butadiene-acrylonitrile elastomer copolymers, polymerization processes.

\section{Introdução}

O butadieno é um monômero utilizado na fabricação de elastômeros de grande interesse econômico no mercado mundial. De acordo com as suas propriedades, os polímeros são designados para um tipo determinado de utilização. Esses elastômeros podem ter propriedades diferentes, em função de sua estrutura química e estereoquímica ${ }^{[1]}$.

Os elastômeros do butadieno mais utilizados comercialmente são o polibutadieno com alto teor de unidades 1,4-cis (BR-alto $c i s$ ), o copolímero de butadieno-estireno (SBR) e o copolímero de butadieno-acrilonitrila (NBR). Dentre esses o mais importante é o SBR, o elastômero sintético mais utilizado mundialmente, principalmente, em pneus ${ }^{[2]}$. O polibutadieno 1,4-cis é muito usado na composição da banda de rodagem além de ser utilizado como modificador de impacto de poliestireno (poliestireno de alto impacto-HIPS) e em resinas $\mathrm{SAN}^{[3]}$. O copolímero elastomérico NBR é empregado em artefatos em que é necessária uma boa resistência a solventes orgânicos e a óleos ${ }^{[4]}$.

A utilização inadequada e indiscriminada de recursos naturais tem gerado situações de desequilíbrio ambiental, algumas temporárias e outras de caráter irreversíve ${ }^{[5]}$. A emissão de gases poluentes na atmosfera, produzidos pelo consumo de combustível, contribui para o aquecimento global e interfere nas mudanças climáticas do planeta ${ }^{[6]}$. Visando minimizar o impacto ambiental causado pela emissão dos gases poluentes na atmosfera, os fabricantes de pneumáticos e de bandas de rodagem têm desenvolvido novos produtos para atender às políticas de gestão ambiental em diversos países ${ }^{[7]}$. Sendo o

Autor para correspondência: Fernanda M. B. Coutinho, Departamento de Processos Químicos, Instituto de Química, UERJ, Rio de Janeiro, RJ. E-mail: fern@pq.cnpq.br 
único meio de contato entre o veículo e o solo, os pneus representam um importante item de desenvolvimento para a diminuição de forças de atrito visando a redução do consumo de combustível $^{[8]}$. O BR-alto is $^{[9-11]}$ e os SBR exibem excelentes propriedades para sua aplicação na produção de pneus, sendo por essa razão, objetos de intensas pesquisas ${ }^{[7]}$.

Os polímeros ou copolímeros do butadieno também são muito empregados em blendas poliméricas, produzidas pela mistura mecânica de dois ou mais polímeros como, por exemplo, NR/SBR (mistura de borracha natural com SBR) ${ }^{[12]}$, NBR/EPDM (mistura de NBR com o copolímero de etilenopropileno-dieno $)^{[13]}$, entre outras. As misturas poliméricas são muitas vezes vantajosas, porque através da mistura de dois polímeros se pode conseguir uma melhoria nas propriedades do material em relação ao polímero puro, assim como também pode ocorrer uma melhoria no processamento, abaixando custo de produção do material ${ }^{[14]}$.

\section{Copolímeros de Butadieno e Estireno (SBR)}

Os mercados mundiais de elastômeros são dominados por dois tipos de borracha, a borracha natural e SBR. Essas borrachas partilham 70 a $75 \%$ do mercado mundial ${ }^{[15]}$. Uma ampla variedade de produtos podem ser feitos com SBR, onde os principais segmentos, que concentram a utilização de SBR, referem-se a pneus e bandas de rodagem ${ }^{[16]}$.

Atualmente, são produzidas no mundo, aproximadamente, 2,4 milhões de toneladas de SBR por ano. As tendências econômicas e tecnológicas das indústrias automotiva e pneumática exercem um papel significativo no seu consumo, pois constituem seu maior mercado ${ }^{[17]}$.

\section{Processos de Síntese para SBR}

O elastômero SBR pode ser produzido por polimerização em emulsão, via radicais livres, (E-SBR) ou por polimerização em solução, via aniônica, (S-SBR $)^{[18,19]}$. A polimerização em emulsão pode ser conduzida tanto a quente quanto a frio. A temperatura exerce um papel importante durante o processo de polimerização e produz elastômeros com propriedades diferentes no produto final ${ }^{[2,15,20]}$.

\section{Polimerização em Emulsão}

A polimerização em emulsão é um processo vantajoso em relação a vários aspectos. Uma dessas vantagens refere-se ao melhor controle da temperatura e da viscosidade do meio reacional (coloidal), que facilita o controle do processo. Uma outra vantagem é que o produto obtido, como látex, pode ser utilizado comercialmente sem que sejam necessárias operações de separação. Tais aplicações comerciais incluem, por exemplo, tintas e revestimentos, entre outros ${ }^{[21]}$. A técnica de polimerização em emulsão é normalmente conduzida sob condições brandas de reação. A água é utilizada como meio dispersante e o principal cuidado a ser tomado é garantir a ausência de oxigênio no meio reacional. Os principais componentes do processo são os monômeros (butadieno e estireno), água, emulsificante e um sistema iniciador ${ }^{[22]}$.

As primeiras borrachas sintéticas de SBR foram produzidas através de um sistema em emulsão, via radicais livres, com iniciador hidrossolúvel, tal como persulfato de potássio, em temperaturas variando de 41 a $50{ }^{\circ} \mathrm{C}$ e utilizando mercaptan de t-dodecila como agente de transferência de cadeia. A conversão do monômero em polímero era conduzida até aproximadamente $72 \%$, ponto em que a reação era interrompida por meio da adição de um agente de terminação. Essa técnica foi denominada polimerização em emulsão a quente, pois o sistema era aquecido. Atualmente, esse tipo de técnica ainda é a base para a polimerização em emulsão a quente ${ }^{[2,15,18,20]}$.

Por volta de 1947, foi desenvolvida a técnica de polimerização em emulsão a frio $\left(5^{\circ}\right)$ para produzir $\mathrm{SBR}^{[23]}$. As principais diferenças entre os processos de polimerização de SBR a quente e a frio são os valores de temperatura e o tipo de sistema iniciador. Tais diferenças no processo de síntese exercem grande efeito nas propriedades do produto final ${ }^{[18,20]}$. O sistema iniciador utilizado no processo em emulsão a frio é um sistema redox constituído por um sal ferroso e um hidroperóxido $(\mathrm{ROOH})$. Os radicais iniciadores são formados pela reação entre o hidroperóxido e o íon ferroso. É utilizado um sulfoxilato com o objetivo de regenerar o sal ferroso durante o processo de polimerização. Na polimerização em emulsão a quente o iniciador utilizado é um persulfato. Em ambos os processos, tanto a quente quanto a frio, são utilizados mercaptans, que atuam como agentes de transferência de cadeia para evitar a formação de polímero com altíssimos valores de peso molecular, indesejável para o processamento do elastômero ${ }^{[20,23]}$. Polímeros diênicos podem sofrer reticulações durante a polimerização, que levam à formação de "gel". Por essa razão, mercaptans são usados como "reguladores" de peso molecular ${ }^{[24]}$. A Tabela 1 mostra os principais componentes dos processos para produzir SBR em emulsão ${ }^{[20]}$.

Tabela 1. Condições de processo e componentes ${ }^{\mathrm{a}}$ utilizados na polimerização em emulsão para produzir SBR ${ }^{[20]}$.

\begin{tabular}{lcc}
\hline $\begin{array}{c}\text { Condições e componentes } \\
\text { do processo }\end{array}$ & $\begin{array}{c}\text { SBR a } \\
\text { quente }\end{array}$ & $\begin{array}{c}\text { SBR a } \\
\text { frio }\end{array}$ \\
\hline Temperatura de polimerização $\left({ }^{\circ} \mathrm{C}\right)$ & 50 & 5 \\
Tempo de polimerização $(\mathrm{h})$ & 12 & 12 \\
Conversão $(\%)$ & 72 & $60-65$ \\
Butadieno (\%) & 71 & 71 \\
Estireno (\%) & 29 & 29 \\
Água & 190 & 190 \\
Emulsificante & 5 & $4,5-5$ \\
Persulfato de potássio & 0,3 & - \\
Mercaptan de n-dodecila & 0,5 & - \\
Mercaptan de t-dodecila & - & 0,2 \\
Hidroperóxido de p-mentila & - & 0,08 \\
Fosfato de sódio $\left(\mathrm{Na}_{3} \mathrm{PO}_{4} \cdot 10 \mathrm{H}_{2} \mathrm{O}\right)$ & - & 0,5 \\
Sulfato ferroso $\left(\mathrm{FeSO}_{4} \cdot 7 \mathrm{H}_{2} \mathrm{O}\right)$ & - & 0,4 \\
Formaldeído sulfoxilato de sódio $(\mathrm{SFS})$ & - & 0,10 \\
EDTA & - & 0,06 \\
\hline
\end{tabular}

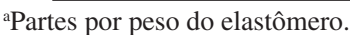


Durante a polimerização, parâmetros tais como temperatura e agitação são controlados para que se alcance alta conversão. No processo de polimerização a quente, normalmente, deixa-se que a conversão atinja $70 \%$ e no processo a frio, $60 \%$, para só então se adicionar o agente de terminação. Os agentes de terminação reagem rapidamente com os radicais livres do meio, interrompendo a propagação das cadeias. Os agentes de terminação, mais comumente utilizados, são o dimetil-ditiocarbamato de sódio e o dietilhidroxilamina $^{[18,23]}$.

Assim que a conversão desejada é atingida, os monômeros não reagidos são retirados do látex. O butadieno é retirado por desgaseificação do látex por meio de destilação, reduzindo a pressão do sistema. O estireno é removido, por arraste de vapor, pela passagem do látex através de uma coluna de stripping ${ }^{[25]}$. O látex é então estabilizado com um antioxidante apropriado e transferido para o tanque de mistura $^{[26]}$.

Antes da coagulação e secagem do látex, quando a viscosidade do polímero ainda é baixa, normalmente, são adicionados óleos extensores, negro de fumo ou ambos. A adição desses componentes, ainda na planta de polimerização, auxiliam o processamento do elastômero. O SBR proveniente de uma planta de polimerização em que se adicionam óleos extensores antes da secagem do látex é chamado SBR óleoestendido. Já o SBR que recebeu negro de fumo ou outros componentes, antes da secagem, é denominado comercialmente como SBR masterbatches ${ }^{[2]}$. O látex é, então, transferido para o sistema de coagulação. O tipo de sistema de coa- gulação é selecionado de acordo com a aplicação do produto final. Após a coagulação, o polímero é lavado, desidratado, seco, embalado e empacotado ${ }^{[23]}$. A Figura 1 mostra o fluxograma de uma planta para produção de SBR em emulsão e a Figura 2 apresenta um diagrama de coagulação e secagem do látex produzido.

\section{Características e Propriedades Mecânicas de SBR obtido por Polimerização em Emulsão}

Os SBR, produzidos por polimerização em emulsão, são comercializados de acordo com a sua viscosidade Mooney, que varia na faixa de 30 a 120 , de acordo com o peso molecular. Os E-SBR, com mais baixos valores de viscosidade Mooney, apresentam maior facilidade de incorporação de cargas e óleos, produzem menos calor durante a mistura, encolhem menos, apresentam maiores velocidades de extrusão e a aparência do extrusado é melhor do que a dos de mais alto valor de viscosidade Mooney. Contudo, E-SBR, de mais alto valor de viscosidade Mooney, apresentam maior resistência do cru, menor porosidade do vulcanizado e aceitam maior quantidade de cargas e óleos ${ }^{[23]}$. Na verdade, esse tipo de comportamento, em relação ao processamento, se deve tanto ao peso molecular do polímero quanto à distribuição de peso molecular. SBR produzidos por polimerização em emulsão apresentam larga distribuição do peso molecular, o que facilita o processamento ${ }^{[27]}$.

Assim como o peso molecular, a arquitetura molecular, representada pelo grau de ramificações, tem grande influên-

(6)

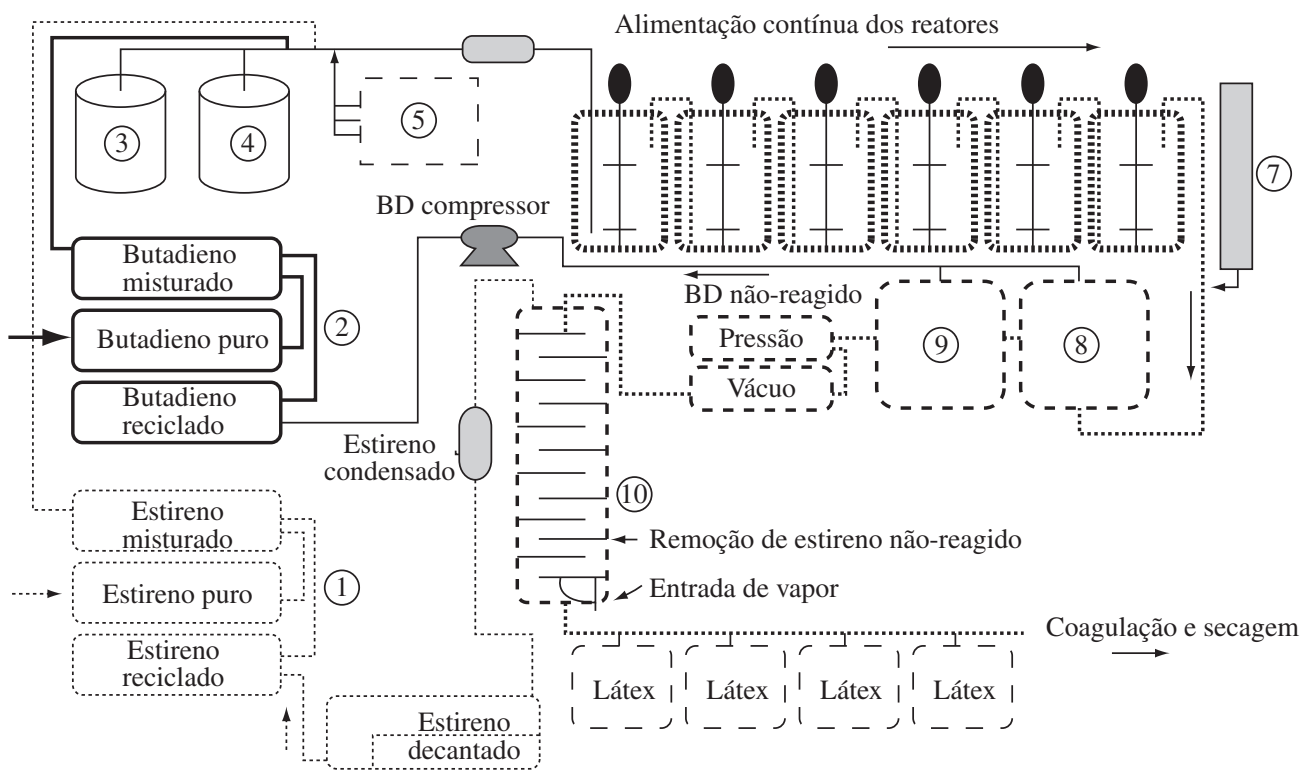

Figura 1. Planta de produção do látex de SBR em emulsão ${ }^{[23]}$. 1) Tanques contendo estireno reciclado (estireno não-reagido), estireno puro e estireno misturado (mistura de estireno reciclado com estireno puro). A mistura é feita para garantir que o estireno da reação tenha uma pureza de cerca de $94 \% ; 2$ ) Tanques contendo butadieno reciclado (butadieno não-reagido), butadieno puro e butadieno misturado (mistura de butadieno reciclado com butadieno puro). A mistura é feita para garantir que o butadieno da reação tenha uma pureza de cerca de 94\%; 3) Emulsificante; 4) Água tratada para reação; 5) Ativador, oxidante e modificador; 6) Reatores de polimerização; 7) Agentes de terminação; 8) Primeiro tanque de remoção de butadieno não-reagido; 9) Segundo tanque de remoção de butadieno não-reagido; 10) Torre de stripping; e 11) Tanques de estocagem do látex. 


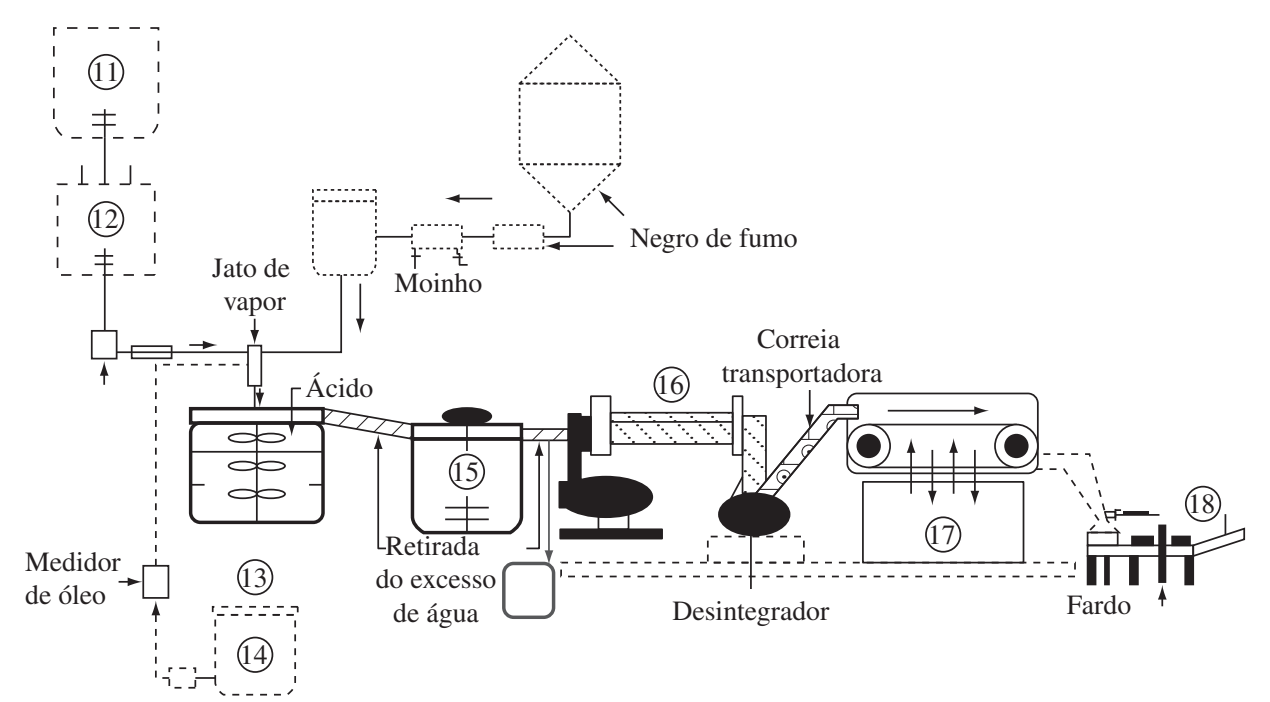

Figura 2. Coagulação e secagem do látex ${ }^{[23]}$. 11) Tanques de estocagem do látex; 12) Adição do antioxidante; 13) Coagulação; 14) Tanque de estoque de óleos aromáticos; 15) Tanque de lixiviação 16) Rosca de compressão para retirada do excesso de água; 17) Secagem do elastômero; e 18) Fardo do elastômero pronto para ser embalado.

cia na viscosidade do polímero. A introdução de ramificações em uma cadeia polimérica está relacionada com a alteração no movimento cooperativo dos segmentos das cadeias. Dependendo da geometria das cadeias, as ramificações podem acentuar o movimento cooperativo, diminuindo a viscosidade do sistema. Além disso, a possibilidade de pontos de contato entre as cadeias, que são determinantes na viscosidade do polímero, diminui bastante com o teor de ramificações devido à natureza menos compacta da estrutura do polímero ramificado. Contudo, alguns pesquisadores afirmam que se as ramificações forem longas o bastante para se entrelaçarem (entanglements), a viscosidade pode aumentar ${ }^{[28]}$ Para o SBR, produzido em emulsão, a temperatura de polimerização tem um papel importante sobre o grau de ramificações do polímero. E-SBR produzido a quente é acentuadamente mais ramificado do que o produzido a frio. Esse aumento no teor das ramificações faz com que se formem os entrelaçamentos e conseqüentemente o polímero adquire uma maior rigidez, tornando seu uso comercial mais restrito. No processo a frio, o polímero apresenta um menor teor de ramificações, fazendo com que o polímero seja mais macio. O processo para produzir E-SBR a frio é mais econômico e o polímero tem maior aplicabilidade, sendo utilizado para diversos fins comerciais $^{[15,18,23]}$.

A microestrutura do SBR produzido em emulsão é aleatória. A percentagem de estireno, na maioria dos SBR produzidos em emulsão, varia na faixa de 0 a $50 \%$. Os polímeros de E-SBR de maior interesse comercial contêm, em média, $23 \%$ de estireno. O aumento da percentagem de estireno no E-SBR provoca um aumento na resistência à tração e na dureza do vulcanizado, por outro lado, diminui a resistência à abrasão ${ }^{[23]}$.

A temperatura de polimerização não exerce influência acentuada sobre a microestrutura do polímero. O conteúdo de unidades 1,2-vinila sofre um pequeno aumento com o au- mento da temperatura. O teor de unidades 1,4-trans aumenta com a diminuição da temperatura e o de unidades 1,4-cis aumenta com o aumento da temperatura. Na polimerização a frio, a microestrutura produzida com o butadieno tem, em média, $9 \%$ de unidades 1,4-cis, $54,5 \%$ de 1,4-trans e $13 \%$ de 1,2 -vinila, sendo a percentagem de estireno de $23,5 \%$. O polímero de E-SBR com essa microestrutura possui uma temperatura de transição vítrea $(\mathrm{Tg}) \mathrm{em}$ torno de $-50{ }^{\circ} \mathrm{C}$. Com o aumento da percentagem de estireno no polímero, ocorre um aumento na $\mathrm{Tg}^{[20]}$. Elastômeros com baixos valores de $\mathrm{Tg}$ são caracterizados por possuírem alta histerese e boa aderência no molhado, quando utilizados na manufatura de pneus ${ }^{[29,30]}$. Em relação à microestrutura do E-SBR e suas propriedades mecânicas, o desejável seria obter altos teores de unidades do butadieno regularmente distribuídas pela cadeia, para que ocorresse a cristalização a frio. Contudo, a introdução do comonômero (estireno) interfere na regularidade da cadeia, prejudicando a estereorregularidade necessária para a cristalização a frio ${ }^{[24]}$.

SBR é um polímero apolar e mau condutor de eletricidade. As propriedades elétricas do E-SBR dependem da quantidade e do tipo dos agentes emulsificantes e coagulantes. E-SBR, quando vulcanizado, apresenta resistência a ácidos e bases diluídas, mas incham acentuadamente em meios apolares tais como, gasolina, óleos ou graxas. Devido a essa limitação, SBR não pode ser utilizado em aplicações que necessitem de resistência ao inchamento com solventes à base de hidrocarbonetos ${ }^{[23]}$.

Em relação ao processo de cura, SBR pode ser reticulado com enxofre, peróxidos ou resinas fenólicas. O processamento do SBR pode ser feito em moinhos, misturadores internos ou em extrusoras ${ }^{[31]}$. 
Tabela 2. Tipos básicos de E-SBR ${ }^{[20,23]}$.

\begin{tabular}{|c|c|}
\hline Numeração básica & $\begin{array}{l}\text { Composição e variação nas } \\
\text { condições de polimerização }\end{array}$ \\
\hline 1000 & Polímeros produzidos a quente. \\
\hline 1500 & $\begin{array}{l}\text { Polímeros sem óleos extensores e } \\
\text { produzidos a frio. }\end{array}$ \\
\hline 1600 & $\begin{array}{l}\text { Polímeros sem óleos extensores, } \\
\text { com negro de fumo e produzidos a } \\
\text { frio. }\end{array}$ \\
\hline 1700 & $\begin{array}{l}\text { Polímeros com óleos extensores e } \\
\text { produzidos a frio. }\end{array}$ \\
\hline 1800 & $\begin{array}{l}\text { Polímeros com óleos extensores, } \\
\text { com negro de fumo e produzidos a } \\
\text { frio. }\end{array}$ \\
\hline 1900 & $\begin{array}{l}\text { Polímeros com alto conteúdo de es- } \\
\text { tireno e cargas variadas. }\end{array}$ \\
\hline 2000 & Látex produzido a quente. \\
\hline 2001 & Látex produzido a frio. \\
\hline
\end{tabular}

\section{Tipos de SBR Produzidos por Polimerização em Emulsão}

Há uma grande variedade de E-SBR. Os diferentes tipos de E-SBR são classificados de acordo com a sua composição e com a forma como foram produzidos. Cada uma das classificações básicas inclui variações com respeito à viscosidade Mooney, tipo de coagulação, tipo de emulsificante, quantidade de óleo, tipo e quantidade de negro de fumo, assim como, temperatura de polimerização e porcentagem de estireno ${ }^{[2,15,18,20,23,24]}$. A Tabela 2 mostra os grupos básicos de E-SBR.

\section{Aplicações de SBR Produzidos por Polimerização em Emulsão}

A principal aplicação para E-SBR é na indústria de pneus. Entretanto, existem diversas outras aplicações que estão listadas na Tabela $3^{[23]}$.

\section{Polimerização em Solução}

A polimerização de SBR em solução tem algumas vantagens sobre o processo em emulsão. Entre essas vantagens, as que merecem maior destaque são o fácil controle da microestrutura e do peso molecular do polímero ${ }^{[15,20]}$. O mecanismo da polimerização de SBR em solução é aniônico. Os iniciadores normalmente utilizados são constituídos por um composto alquil lítio ${ }^{[32]}$. Os solventes que tanto podem ser polares quanto apolares, interferem na microestrutura das cadeias formadas. Se a polimerização for conduzida em solventes apolares (hexano, ciclo-hexano), o butadieno polimeriza primeiro e apenas quando quase todo o butadieno tiver sido consumido é que o estireno começa a polimerizar. Esse tipo de solvente conduz à formação de SBR em bloco ${ }^{[15]}$. O fato de o butadieno ser mais reativo do que o estireno, em meio apolar, se deve a sua mais baixa polaridade. Assim, o butadieno sendo um monômero apolar é melhor solvatado por solventes apolares, resultando no aumento de sua constante de velocidade de propagação $(\mathrm{kp})^{[33]}$. Para produzir polímeros com distribuição aleatória dos meros, em solventes apolares, aumenta-se gradativamente a quantidade de butadieno no meio reacional, de forma que a concentração de estireno seja sempre maior que a concentração de butadieno. Outro método para produzir S-SBR aleatório consiste na adição de éteres ou aminas durante o processo de polimerização. Contudo, a presença de solventes polares resulta no aumento do teor de unidades 1,2 -vinila na cadeia polimérica ${ }^{[34]}$. O aumento do teor de unidades 1,2-vinila provoca um aumento na $\mathrm{Tg}$ do polímero, que dependendo da aplicação, se torna uma característica desejável ou indesejável ${ }^{[35]}$. Para o caso da aplicação em bandas de rodagem de pneus, o aumento do teor de unidades 1,2-vinila pode ser de grande interesse, pois a resistência à derrapagem aumenta com o aumento da $\mathrm{Tg}^{[36]}$. Uma outra alternativa para produzir polímeros aleatórios é a

Tabela 3. Principais aplicações para SBR em emulsão ${ }^{[23]}$

\begin{tabular}{|c|c|c|c|c|}
\hline \multirow[b]{2}{*}{ Aplicações } & \multirow[b]{2}{*}{ Polimerização a quente } & \multicolumn{2}{|c|}{ Polimerização a frio } & \multirow[b]{2}{*}{$\begin{array}{c}\text { Alto conteúdo de } \\
\text { estireno com cargas }\end{array}$} \\
\hline & & Sem óleos extensores & Com óleos extensores & \\
\hline Etiquetas & $\bullet$ & $\bullet$ & $\bullet$ & \\
\hline Calafetagem & $\bullet$ & & & \\
\hline Laminação & $\bullet$ & $\bullet$ & & \\
\hline Argamassa & $\bullet$ & & & \\
\hline Painel & $\bullet$ & & & \\
\hline Bandas de rodagem & & $\bullet$ & & \\
\hline Aro de pneu & & & & $\bullet$ \\
\hline Carcaça do pneu & & $\bullet$ & $\bullet$ & \\
\hline Face de rolamento & & $\bullet$ & $\bullet$ & \\
\hline Pneus de corrida & & & $\bullet$ & \\
\hline Esteiras & & $\bullet$ & $\bullet$ & $\bullet$ \\
\hline Reforço mecânico & $\bullet$ & $\bullet$ & $\bullet$ & $\bullet$ \\
\hline Gaxetas & & $\bullet$ & $\bullet$ & $\bullet$ \\
\hline Cintos / mangueiras & & $\bullet$ & $\bullet$ & \\
\hline Calçados & & $\bullet$ & $\bullet$ & $\bullet$ \\
\hline Revestimentos de cabos & & $\bullet$ & & \\
\hline
\end{tabular}


utilização de butóxido de potássio, ao invés de éteres e aminas. A vantagem da utilização desse alcóxido é que os polímeros produzidos apresentam menores teores de unidades 1,2-vinila ${ }^{[15,34]}$.

Maiores teores de unidades 1,4-cis são produzidos quando são utilizados solventes apolares. Essa maior porcentagem de unidades 1,4-cis no S-SBR traz vantagens quando se deseja obter um material com características mais elastoméricas à temperatura ambiente ${ }^{[37]}$. Estudos recentes, sobre a polimerização aleatória de estireno-butadieno em solução, revelaram que, um alto teor de unidades 1,4-trans (cerca de 73\%) e baixa percentagem de estireno (valores menores que 30\%) garantem uma maior resistência do elastômero ao desgaste. Essa propriedade é muito importante em bandas de rodagem de pneus, principalmente em pneus de caminhões, que necessitam suportar o esforço acentuado das cargas pesadas ${ }^{[38,39]}$.

O peso molecular do S-SBR pode ser facilmente controlado. O mecanismo e a cinética da polimerização em solução aniônica sugerem que a iniciação é instantânea. Presumindose que as cadeias têm a mesma oportunidade de crescimento e que não há impurezas no meio reacional, a distribuição de peso molecular será estreita. O valor do peso molecular do SBR pode ser controlado por meio de um agente de terminação ${ }^{[21]}$.

Recentemente, foram desenvolvidos novos iniciadores, baseados em metais de transição, para produzir $\mathrm{SBR}^{[40]}$. Um estudo envolvendo iniciadores homogêneos à base de níquel (Ni) e metilaluminoxano (MAO) foi realizado. Nesse estudo verificou-se um aumento no teor de unidades 1,4-cis no SBR. A vantagem desses sistemas é a possibilidade de maior controle da microestrutura, determinada pela alta estereoespecificidade dos catalisadores.

\section{Características e Propriedades Mecânicas do S-SBR}

Os polímeros de SBR produzidos pelo processo em solução podem apresentar características distintas, que variam de acordo com as condições do processo. Em função da microestrutura do S-SBR, o polímero irá apresentar propriedades físicas adequadas para determinado tipo de aplicação ${ }^{[24]}$. De uma forma geral, S-SBR apresenta algumas características vantajosas sobre E-SBR, que refletem em suas propriedades mecânicas. Entre essas vantagens estão a disponibilidade de uma ampla faixa de colorações, pois não há necessidade de se utilizar estabilizantes que manchem o produto, é necessária menor quantidade de cargas, os produtos extrusados têm estabilidade dimensional, maior velocidade de cura e os vulcanizados têm maior resistência ao rasgo e melhor resistência à abrasão ${ }^{[15]}$. Contudo, os S-SBR apresentam alguns problemas quanto à incorporação de cargas e à processabilidade devido à estreita distribuição de peso molecular. Em elastômeros, como SBR, é de grande importância que o material apresente baixa histerese, principalmente quando o elastômero for utilizado em bandas de rodagem de pneus ${ }^{[41]}$. Tais elastômeros são aditivados com enxofre, negro de fumo ou síli- ca, aceleradores, antidegradantes antes de serem curados ou vulcanizados $^{[27]}$. As propriedades físicas do elastômero estão relacionadas com o modo como o negro de fumo é incorporado. Se o negro de fumo não for homogeneamente incorporado no elastômero, as propriedades físicas do material são prejudicadas. Um exemplo importante refere-se à resistência ao rolamento da banda de rodagem de pneus, que pode ser aumentada pelo aumento da afinidade entre o elastômero e o negro de fumo. A processabilidade também pode ser afetada pela má incorporação das cargas. Estudos recentes (patentes e artigos) resolveram o problema da incorporação de cargas em S-SBR através do uso de aminas durante o processo de polimerização $o^{[41]}$. A amina é incorporada nos terminais de cadeia do elastômero facilitando a dispersão do negro de fumo. Desse modo, há aumento na elasticidade, proporcionando uma redução na histerese dos compostos das bandas de rodagem de pneus e, conseqüentemente, promove a redução da resistência ao rolamento ${ }^{[41]}$. Uma patente contorna o problema da processabilidade por meio da incorporação de ramificações ao longo das cadeias do S-SBR ${ }^{[27]}$.

\section{Aplicações de SBR Obtidos por Polimerização em Solução}

As aplicações de S-SBR são praticamente as mesmas apresentadas na Tabela 3 para os E-SBR. As aplicações que merecem maior destaque são encontradas na indústria de calçados $(78 \%)$ e na indústria de pneus $(14 \%)^{[21]}$.

\section{Copolímero de Butadieno e Acrilonitrila (NBR)}

O copolímero elastomérico constituído de acrilonitrila e butadieno, também comumente conhecido por borracha nitrílica, apresenta um acentuado interesse econômico. Comercialmente disponível há, aproximadamente, 60 anos, NBR tem grande utilização, principalmente, devido a sua resistência a solventes apolares ${ }^{[42]}$. Essa característica é interessante, do ponto de vista comercial, quando são necessários materiais resistentes a solventes à base de hidrocarbonetos. $\mathrm{Na}$ indústria automotiva, NBR é utilizado em artefatos que tenham contato direto com combustíveis ${ }^{[43]}$. NBR também é bastante utilizado em misturas com outros elastômeros, para aumentar a resistência a óleos desses elastômeros ${ }^{[44]}$.

O consumo anual, esperado para o ano de 2007, é de aproximadamente 368.000 toneladas métricas por ano. $\mathrm{O}$ alto valor de consumo de NBR esperado, mostra a importância desse elastômero ${ }^{[45]}$.

\section{Processos de Síntese}

NBR é produzido por polimerização em emulsão, que pode ser conduzida tanto a quente como a frio. No processo em emulsão a quente a faixa de temperatura utilizada situa-se entre 30 e $40{ }^{\circ} \mathrm{C}$. Esse processo produz polímeros altamente ramificados. Na polimerização a frio a temperatura de poli- 
merização varia entre 5 e $15{ }^{\circ} \mathrm{C}$ e são produzidos polímeros mais lineares em relação ao processo a quente ${ }^{[2,15]}$. Conforme acontece com SBR, os dois monômeros (butadieno e acrilonitrila) possuem reatividades diferentes, sendo a acrilonitrila mais reativa, esta é consumida antes do butadieno. Assim, a acrilonitrila é adicionada em vários estágios durante a reação de polimerização para que se obtenha um produto razoavelmente uniforme ${ }^{[15]}$

Existe uma ampla variedade de composições para NBR. Essas variações na composição do elastômero determinam diferenças importantes entre os vários tipos comerciais. Entre essas variações estão o conteúdo de acrilonitrila no elastômero (15 a 51\%), monômeros adicionais, peso molecular, distribuição de peso molecular, teor de ramificações, microestrutura e estabilizantes incorporados no produto ${ }^{[15,43,46]}$. A percentagem dos monômeros na composição do elastômero parece ser o fator de maior influência nas características do produto final. Dependendo do teor de acrilonitrila ou butadieno no elastômero, o produto terá propriedades químicas e físicas diferentes. A estrutura química do NBR contém duplas ligações (geradas pelo butadieno) e o grupamento polar nitrila. A dupla ligação permite a vulcanização com enxofre, mas também é suscetível à oxidação e ataque por ozônio. $\mathrm{O}$ grupo nitrila confere resistência a óleos e solventes à base de hidrocarbonetos, entretanto, tende a aumentar o valor da $\mathrm{Tg}$ do elastômero ${ }^{[47]}$. Dessa forma, dependendo da aplicação do produto, o fabricante determina a composição do elastômero. Na Figura 3 é mostrada a estrutura química do NBR, indicando as três possíveis estruturas isoméricas para os meros do butadieno $0^{[45]}$.

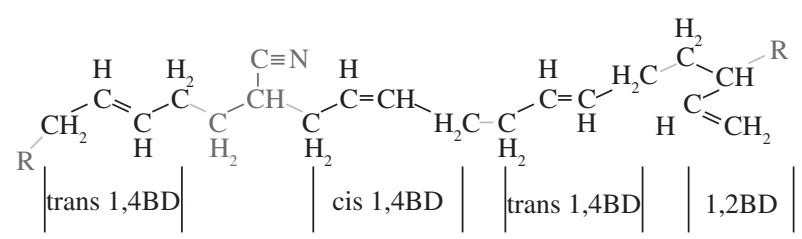

Figura 3. Possível estrutura para $\mathrm{NBR}^{[45]}$.
Polímeros especiais de NBR, com um terceiro monômero, também podem ser produzidos. $\mathrm{O}$ terceiro monômero pode ser o divinilbenzeno ou o ácido metacrílico. O objetivo da incorporação do novo monômero é melhorar certas propriedades físicas ${ }^{[45,47]}$. Alguns elastômeros de NBR são hidrogenados, a hidrogenação confere ao material maior resistência química ${ }^{[48]}$.

\section{Características e Propriedades Mecânicas de NBR}

O teor de acrilonitrila é um dos principais critérios para definir as propriedades básicas do elastômero. A polaridade do grupamento nitrila faz com que o elastômero apresente resistência a óleos e solventes à base de hidrocarbonetos e apresente também boa flexibilidade e resistência à abrasão ${ }^{[49]}$. A Tabela 4 apresenta as principais propriedades do NBR. A direção das setas indica um aumento dos valores da propriedade do NBR em relação ao conteúdo de acrilonitrila ${ }^{[45]}$.

NBR produzidos pelo processo a quente são elastômeros altamente ramificados. As ramificações fazem com que o polímero apresente boa aderência e assim, tenha boa aplicação como adesivo ${ }^{[49,45]}$. Os entrelaçamento das cadeias (entanglements) também fornecem ao elastômero um acentuado aumento na resistência ao rasgo ${ }^{[28]}$.

A adição de grupos carboxílicos ao NBR altera acentuadamente o processamento e a cura. $\mathrm{O}$ resultado é uma matriz polimérica com maior resistência à tração, resistência ao rasgo e resistência à abrasão. Contudo, diminui a resistência à água, resiliência e algumas propriedades a baixas temperaturas ${ }^{[50]}$.

\section{Aplicações de NBR}

As principais aplicações de NBR são na indústria automotiva. NBR, normalmente, é utilizado em mangueiras que tenham contato direto com combustíveis ou gases. NBR também é bastante utilizado em misturas com outros elastômeros, para aumentar a resistência a óleos da mistura ${ }^{[2-45]}$.

Tabela 4. Propriedades de NBR relacionadas ao teor de acrilonitrila ${ }^{[45]}$.

\begin{tabular}{|c|c|c|}
\hline $\begin{array}{c}\text { NBR com menor percentagem } \\
\text { de acrilonitrila }\end{array}$ & Propriedades & $\begin{array}{c}\text { NBR com maior percentagem } \\
\text { de acrilonitrila }\end{array}$ \\
\hline & Processabilidade & $\rightarrow$ \\
\hline & Taxa de cura com enxofre & $\rightarrow$ \\
\hline & Resistência a óleos & $\rightarrow$ \\
\hline & Compatibilidade com polímeros polares & $\rightarrow$ \\
\hline & Impermeabilidade a gases e ar & $\rightarrow$ \\
\hline & Resistência à tração & $\rightarrow$ \\
\hline & Resistência à abrasão & $\rightarrow$ \\
\hline & Resistência ao envelhecimento & $\rightarrow$ \\
\hline$\leftarrow$ & Taxa de cura com peróxido & \\
\hline$\leftarrow$ & Resiliência & \\
\hline$\leftarrow$ & Histerese & \\
\hline$\leftarrow$ & Flexibilidade a baixas temperaturas & \\
\hline
\end{tabular}




\section{Agradecimentos}

Ao CNPq, à FAPERJ e à Petroflex Indústria e Comércio pelo apoio financeiro

\section{Referências Bibliográficas}

1. Lynch, J. - "BD monomer and elastomer production processes"; Chemico-Biological Interactions, 135-136, p.147-153 (2001)

2. Tate, D. P. - "Butadiene Polymers". in: "Encyclopedia of Polymer Science and Engineering", Mark; Bikales; Overberg; Menges. (ed.): John Wiley \& Sons, 2, p.537-579 (1986).

3. International Institute of Synthetic Rubber Producers; "Polybutadiene", Worldwide Polymers, Houston, 2004.

4. Guerin, F.; Hannay, J.; Campomizzi, E. \& Bender, H. "Nitrile polymer vulcanizate and process for the production thereof"; US 20030176587 (2003).

5. Menezes, V. J. - “Avaliação das emissões oriundas da degradação térmica de pneus", Dissertação de Mestrado, Instituto de Macromoléculas Professora Eloísa Mano, Universidade Federal do Rio de Janeiro (2005).

6. Mello, I. L.; Coutinho, F. M. B.; Nunes, D. S. S. \& Soares, B. G. - Polímeros: Ciência e Tecnologia, São Carlos, 14, p.235-241 (2004).

7. "Novos elastômeros para os segmentos de pneus e bandas", Borracha Atual, 39, p.40-43 (2002).

8. Rocha, T. C. J.; Coutinho, F.M.B.; Soares, B. G. \& Costa, M. A. da S. - Polímeros: Ciência e Tecnologia, São Carlos, 15, p.39-45 (2005).

9. Pires, N.M.T.; Coutinho, F.M.B.; Costa, M.A.S.; Santa Maria, L.C.; Mello, I.L. \& Nunes, D.S.S. - Revista de Química Industrial 719, p.15-20 (2002).

10. Mello, I. L. - "Efeito do solvente na polimerização 1,4cis de 1,3-butadieno com catalisador à base de neodímio", Dissertação de Mestrado, Instituto de Macromoléculas Professora Eloísa Mano, Universidade Federal do Rio de Janeiro (2003).

11. Rocha, T. C. J. - "Efeito de doadores de elétrons na polimerização de butadieno com catalisadores à base de neodímio", Dissertação de Mestrado, Instituto de Macromoléculas Professora Eloísa Mano, Universidade Federal do Rio de Janeiro (2004).

12. Visconte, L. L. Y.; Martins, A. F.; Nunes, R. C. R.; Suarez \& J. C. M. - Polímeros: Ciência e Tecnologia, XI, p.76-81 (2001).

13. Oliveira, M. G. \& Soares, B. G. - Polímeros: Ciência e Tecnologia, XII, p.11-1 (2002).

14. Ferreira, A. de A. - "Estudo do efeito da cristalinidade do polibutadieno alto-cis sobre as propriedades me- cânicas de suas composições com negro de fumo elou elastômero de butadieno-estireno", Tese de Doutorado, Instituto de Macromoléculas Professora Eloísa Mano, Universidade Federal do Rio de Janeiro (2004).

15. Brydson, J. A.; "Rubbery materials and their compounds"; Elsevier Science Publishers Corporation, Inc.; New York, (1ª edição) (1988).

16. "Tendências 2002 moderadas expectativas para o ano", Borracha Atual, 38, p.32-36, (2002).

17. International Institute of Synthetic Rubber Producers Worldwide Rubber Statistics", Houston, 1999.

18. Colvin, A. H. \& Senyek, M. L. - "Emulsion styrene-butadiene rubber"; US 20020061955 (2002).

19. Coutinho, F. M. B. \& Oliveira, C. M. F. - "Reações de polimerização em cadeia - Mecanismo e cinética". Interciência, Rio de Janeiro, 2006.

20. Quirk, R. P. \& Morton, M.; "Polymerization”, In: “Science and Technology of Rubber", Mark, J. E.; Erman, B.; Eirich, F. R. (ed.): Academic Press, Inc., San Diego, 1994, cap. 2, p. 23-86.

21. Odian, G. G.; "Principles of Polymerization"; John Wiley \& Sons, Inc.; New York, (3 edição) (1991).

22. Mano, E.B. \& Mendes, L. C. - "Introdução a Polímeros", Editora Edgard Blücher Ltda (1999).

23. International Institute of Synthetic Rubber Producers "Emulsion styrene-butadiene rubber (E-SBR)", Worldwide Polymers, Houston, 2004.

24. Morton, M. - "Rubber Technology"; Kluwer Academic Publishers, Inc.; New York, (4a edição) (1999).

25. Hirota, W. H.; Reis, M. M.; Sayer, C. \& Giudici, R. - Polímeros: Ciência e Tecnologia, XIV, p. 51-56, (2004).

26. Grimm, J. - "Method for the production of nitrile rubber"; US 5708132, (1998).

27. Viola, G. T.; Soddu, L.; Isidori, S.; Taccioli, A. \& Masi, F. - "Process for the preparation of sbr rubbers with an improved processability and a lower rolling resistance"; US 20040006187 (2004).

28. Navarro, R. F.; "Fundamentos de reologia de polímeros", Editora da Universidade de Caxias do Sul, Caxias do Sul, (1 ${ }^{\text {a }}$ edição) (1997).

29. Backley, D. C.; "Synthetic Rubbers: Their Chemistry and Technology"; Applied Science Publishers, London, 1983.

30. Rocha, T. C. J.; Coutinho, F. M. B.; Soares, B. G.; Costa, M. A. da S.; Nunes, D. S. S. \& Mello, I. L. - Journal of Applied Polymer Science, New Jersey, 98, p.25392543, (2005).

31. Basfar, A. A.; Abdel-Aziz, M. M. \& Mofti, S. - Radiation Physics and Chemistry, 63, p.81-87 (2002). 
32. International Institute of Synthetic Rubber Producers; "Styrenic block copolymers", Worldwide Polymers, Houston, 2004.

33. Zanzig, J. D.; Holden, D. B. - "Tire with component of rubber composition comprised of a combination of functional SBR and coupled solution SBR"; US 2004054062 (2004).

34. Hesterwerth, D.; Beckelmann, D. \& Bandermann, F. Journal of Applied Polymer Science, 73, p.1521-1532 (1999).

35. Aggarwal, S. L.; Hargis, I. G., Livigni, R. A.; Fabris, H. J. \& Marker, L. F. - "Structure and properties of tire rubbers prepared by anionic polymerization". in: "Advances in Elastomers and Rubber Elasticity", (ed.): Plenum Press Publishers Corporation, New York, p.1736 (1986).

36. Klopffer, M.; Bokboza, L.; Monnerie, L. - Polymer, 39 p.3445-3449 (1998).

37. Labauze, G. J. - "Rubber composition for tire tread and tire"; US 20040122157 (2004).

38. Weydert, M.; Thielen, G. M. V. \& Halasa, A. F. - "Pneumatic tire having a component containing high trans styrene-butadiene rubber"; US 20040108034 (2004).

39. Sandstrom, P. H. - "Tire with rubber composition"; US 20040116574 (2004).

40. Endo, K.; Senoo, K. \& Yamanaka, Y. M. - "Homopolymerization and copolymerization of styrene and butadiene with nickelocene-methylaluminoxane catalyst". in: "Progress and development of catalytic olefin polymerization", Sano, T.; Uozumi, T.; Nakatani, H.; terano, M. (ed.): Technology and Education publishers, Tokyo, p. 98-104, (2000).
41. Halasa, A. F.; Hsu, W.; Zhou, J.; Jasiunas, C. A. \& Yon, C. S. - "Functionalized monomers for synthesis of rubbery polymers"; US 20040122224 (2004).

42. Lightsey, J. W. - "Continuous polymerization process for producing NBR rubber having bound content of acrylonitrile"; US 5770660 (1998).

43. Iozzi, M. A.; Martins, M. A.; Mattoso, H. C. - Polímeros: Ciência e Tecnologia, XIV, p.93-98 (2004).

44. Almeida, M. S.; Soares, B. G. \& Guimarães, P. I. C. Polímeros: Ciência e Tecnologia, XIII, 2. p.119-124 (2003).

45. International Institute of Synthetic Rubber Producers; "Acrylonitrile-butadiene rubber (NBR)", Worldwide Polymers, Houston (2006).

46. Dunn, E. R. \& Burroway, G. L. - "Process for increasing the solids content of nitrile rubber latex"; US 5677368 (1997).

47. Lipinski, T. M. "Soft nitrile rubber formulation"; US 6031042 (2000).

48. Guerin, F. Guo, S. X.; Szentivanyi, Z. \& Glander, S. "Low molecular weight hydrogenated nitrile rubber"; US 6780939 (2004).

49. Oyama, M.; Aimura, Y.; Nakajima, K.; Mori, O. \& Ishihara, M. - "Highly saturated nitrile rubber, process for producing same, vulcanizable rubber composition, aqueous emulsion and adhesive composition"; US 5651995 (1997).

50. Sandstrom, P. H. - "Sulfur cured rubber composition containing chlorosulfonated polyethylene and carboxilated nitrile rubber"; US 6218473 (2001).

Enviado: $11 / 01$

Reenviado: $11 / 04$

Aceito: $23 / 04$ 